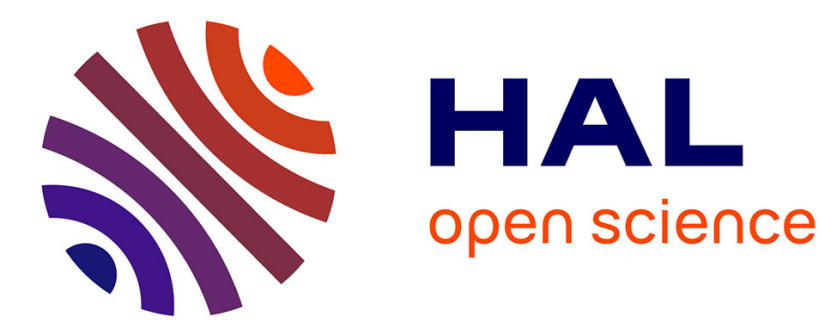

\title{
Darcy Scale Modeling of Smoldering: Impact of Heat Loss
}

Victor Pozzobon, Germain Baud, Sylvain Salvador, Gérald Debenest

\section{To cite this version:}

Victor Pozzobon, Germain Baud, Sylvain Salvador, Gérald Debenest. Darcy Scale Modeling of Smoldering: Impact of Heat Loss. Combustion Science and Technology, 2017, 189 (2), pp.340-365. 10.1080/00102202.2016.1214585 . hal-01619244

\section{HAL Id: hal-01619244 https://hal.science/hal-01619244}

Submitted on 17 May 2018

HAL is a multi-disciplinary open access archive for the deposit and dissemination of scientific research documents, whether they are published or not. The documents may come from teaching and research institutions in France or abroad, or from public or private research centers.
L'archive ouverte pluridisciplinaire HAL, est destinée au dépôt et à la diffusion de documents scientifiques de niveau recherche, publiés ou non, émanant des établissements d'enseignement et de recherche français ou étrangers, des laboratoires publics ou privés. 


\title{
Darcy Scale Modeling of Smoldering: Impact of Heat Loss
}

\author{
Victor Pozzobon (1) ${ }^{a}$, Germain Baud ${ }^{\mathrm{a}}$, Sylvain Salvador ${ }^{\mathrm{a}}$, and Gerald Debenest ${ }^{\mathrm{b}}$ \\ aUniversité de Toulouse, Mines Albi, centre RAPSODEE, Campus Jarlard, Albi, France; 'blnstitut de Mécanique \\ des Fluides de Toulouse, Toulouse, France
}

\begin{abstract}
Modeling the propagation of smoldering fronts with forced air feeding in a porous medium remains a challenge to science. One of the main difficulties is to describe the carbon oxidation reaction that supports this self-sustained process. Pore scale approaches are required to tackle this complex coupled heat and mass transfer problem with chemistry. They, nevertheless, require high computation effort and still miss experimental validation. Furthermore, the heat loss at the walls of the cells inherent to every laboratory scale system adds another level of complexity in the understanding of the coupling between the phenomena at stake. Indeed, it induces a nonhomogeneous temperature field throughout the system. In this article, a 2D Darcy scale model is developed and validated by confrontation with experimental results from the literature, covering wide ranges of carbon content of the medium and forced air velocity. A reasonable description of the front temperature, velocity, and non-consumption oxygen amount is reached. The model finally enables understanding of the impact of heat loss, which controls the front shape and stability near the system walls.
\end{abstract}

\author{
KEYWORDS \\ Homogeneous porous \\ medium; Modeling; \\ Smoldering
}

\section{Introduction}

Smoldering is a process in which a combustion wave propagates through a porous medium. It is involved in many situations, both naturally and in man-controlled processes. Energy applications (Akkutlu and Yortsos, 2003; Mailybaev et al., 2011), but also environment science (Pironi et al., 2005; Vantelon et al., 2009) and forest management (Page et al., 2008; Rein et al., 2002), are classical areas of application.

The propagation of the combustion wave is a complex problem involving heat and mass transfer together with chemical reactions and sometimes phase changes. Admittedly, the energy required to enable the self-propagation of the wave is brought by the direct and flameless oxidation of some carbon in the medium. Most of the time this carbon is the result of a previous solid fuel devolatilization that leads to the formation of volatile matters-gas and tars-and is sometimes called fixed carbon. As the wave progresses, the endothermic drying of the medium is forced. If the medium contains carbonates, the endothermic decarbonation of the medium occurs when the temperature overpasses approximately $800^{\circ} \mathrm{C}$ (Sennoune et al., 2011).

CONTACT Victor Pozzobon victor.pozzobon@mines-albi.fr E Center de Recherche d'Albi en Genie des Procedes des Solied Divises de 1'Energie et de 1'Environnment, Albi, France. 
The description of these phenomena in numerical models remains a challenge to science. Theoretically, the structure of the filtration combustion front was analyzed in 1D-geometry, like in the study of Aldushin et al. (1980). Several others can be found depending on the methods, but also on the operating conditions, i.e., cocurrent and countercurrent situations (Schult et al., 1995, 1998). In all of these studies, a simplified chemistry is assumed, usually first-order and Arrhenius-like reactions. Furthermore, the strong coupling existing between heat and mass transport with a complex, multi-step chemistry, depending on local scale thermochemical conditions, is not explicitly addressed. For instance, the wave temperature depends on the amount of heat released from carbon oxidation in the reacting zone. Several recent attempts have been made to study, in detail, images of porous media, the dynamics and regime of such a wave at the pore scale in density variable conditions (Yang and Debenest., 2014) or in non-dilatable situations (Debenest et al., 2005). They clearly demonstrate, using simplified chemistry, the competitive effect between residence time of oxygen in the front and the thermal equilibrium to maintain the combustion process. Increasing the flow rate could lead to unburned carbon and then to transition in thermal wave temperature as in Elayeb (2008). In turn, the front velocity depends on a number of parameters. It is essentially governed by the stoichiometry of the carbon oxidation reaction with the fed oxygen. Nevertheless, this requires that the fraction of carbon actually oxidized and the fraction of oxygen actually consumed by the front-both of which depend on the front temperature-are well predicted.

Also, these transitions in thermal wave transport and combustion regimes affect the chemistry. Usually, we lump all of the reactions representing the carbon oxidation process into a simplified model. This has been done in Martins et al. (2010) and Fadaei et al. (2012). A global description of this very complex process can be given as:

$$
\mathrm{C}+\left(1-\frac{f r_{\mathrm{CO}}}{2}\right) \mathrm{O}_{2} \mapsto f r_{\mathrm{CO}} \mathrm{CO}+\left(1-f r_{\mathrm{CO}}\right) \mathrm{CO}_{2}
$$

where $f r_{C O}$ is the fraction of carbon that is oxidized into CO. The $f r_{C O}$ parameter strongly affects the front velocity. Indeed the velocity varies by a factor of 2 when $f r_{C O}$ changes from 0 to 1 . The energy released at carbon oxidation increases from 110.5 $\mathrm{kJ} /$ mole for $f r_{C O}=1$ to $393.5 \mathrm{~kJ} /$ mole when $f r_{C O}=0$. This will also strongly impact the front temperature.

The prediction by models of the $f r_{C O}$ value is a challenging task. This is due to the fact that the final amount of $\mathrm{CO}$ and $\mathrm{CO}_{2}$ observed depends on a number of parameters, such as the air flow, the front temperature, the medium carbon content, and the geometry of the medium particles. The primary formation of $\mathrm{CO}$ by the heterogeneous reaction of $\mathrm{O}_{2}$ with solid carbon is to be followed by homogeneous oxidation of $\mathrm{CO}$ into $\mathrm{CO}_{2}$, but also by reaction of the formed $\mathrm{CO}_{2}$ with solid carbon. The chemical phenomena are coupled with transport phenomena that impact gas mixing efficiency and solid-gas contact time, as discussed in Zajdlik et al. (2001). Therefore, predicting $f r_{C O}$ from a numerical model can only be tackled at the pore scale. This task remains complex and a review of the possible modeling approaches is presented in Yang et al. (2015), which deals with the upscaling of such a problem from pore scale to Darcy scale. 
In addition to this already complex situation, another inevitable phenomenon occure: heat loss. Indeed, no experimental device is perfectly insulated. Heat loss lowers temperature, thus having an impact on several local physical properties, such as gas density, gas viscosity, and even on the $f r_{C O}$ parameter. This adds another level of complexity in the understanding of the coupling between the phenomena at stake. To summarize, the fact is that the literature does not propose a modeling approach with affordable computation time able to predict a carbon consuming front velocity and temperature, together with the amounts of unburned carbon after the front passage and non-consumed oxygen. In addition, to our knowledge, none of the currently available models properly takes into account the heat loss. Heat loss is described as a volumetric sink term in 1D (Fadaei et al., 2012) or as a prescribed heat flux on the external boundary in 2D (Hasan et al., 2011; Maerefat et al., 2015). One should note that these prescribed heat fluxes have to be experimentally monitored, then provided to the model, which hinders the model's actual predictive culpabilities. Developing a model properly accounting for the heat loss-based on a simple description of carbon oxidation reactionis the purpose of this article. The global strategy is described below:

- A set of 12 experimental results was first established in a previous work (Baud et al., 2015). A situation as simple as possible was aimed for, developing a model medium containing only carbon in an inert matrix of alumina. Two parameters of primary importance were varied in ranges as large as possible: the carbon content between $2.30 \%$ and $3.58 \%$ and the air flux by a factor of 10 . Five experiments in extreme conditions were selected among them.

- A numerical model was developed in this work with the aim of describing the five experiments, properly accounting for the heat loss and keeping the description of carbon oxidation reaction as simple as possible.

The final confrontation of model to experiments will be done to obtain some of the important front characteristics. These depend on the operating conditions, mainly, flow rate and carbon concentration. We will demonstrate the ability of the numerical model to explain the impact of heat loss on the smoldering front.

\section{Experimental device and experimental database}

The combustion cell used to obtain the experimental data bank is described in detail in Baud et al. (2015; Figure 1). Briefly, it consists of a stainless steel tube (91 $\mathrm{mm}$ in diameter, $600 \mathrm{~mm}$ long) filled with a granular reactive porous medium. The tube was thermally insulated using a 50-mm-thick Kaowool HS-45 insulating material around the cylinder.

Air was fed from the top of the cell. Ignition was operated by irradiating the top of the bed with a high density radiative flux of $50 \mathrm{~kW} / \mathrm{m}^{2}$, through a quartz window. Smoldering was therefore operated in the forward configuration.

The reactive porous medium was specially developed to keep the situation as simple as possible. We use porous alumina spheres with diameters ranging from $1.25 \mathrm{~mm}$ to $3.15 \mathrm{~mm}$. They were enriched with solid carbon in controlled amounts thanks to a procedure described in Baud et al. (2015).

To serve as a model validation benchmark, the results from five experiments were selected. In the first three experiments, the carbon content is varied from $2.30 \%$ to $3.58 \%$ 


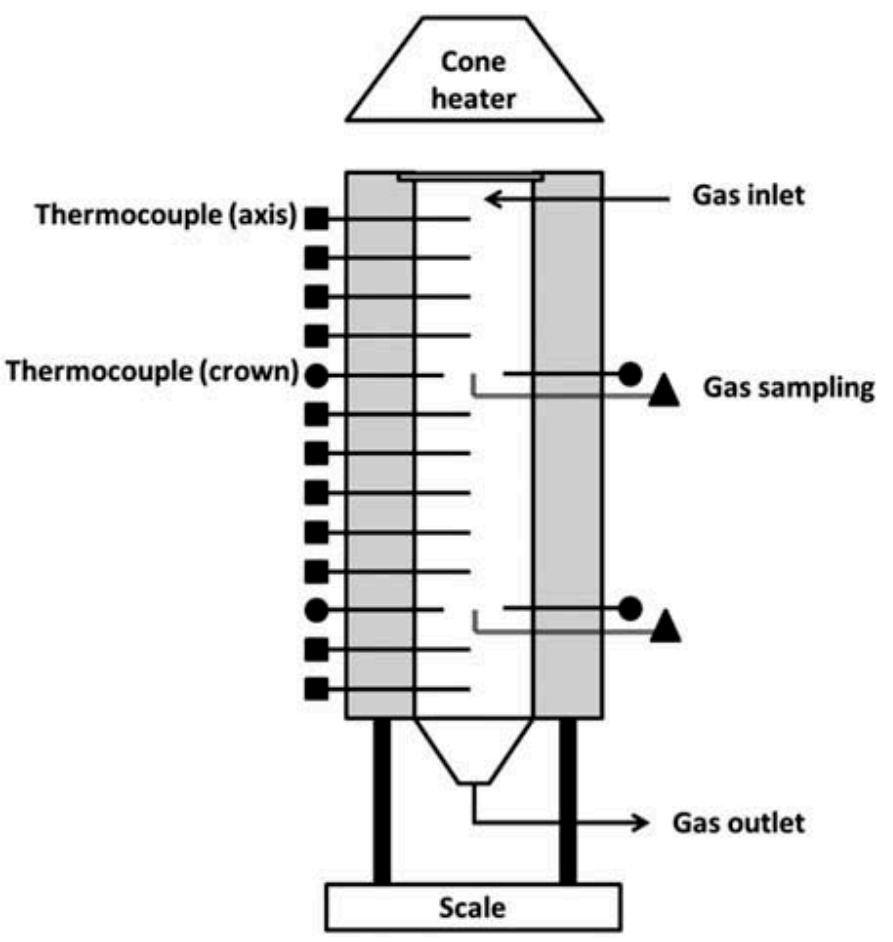

Figure 1. Schematic of the experimental apparatus. [Reprinted with permission from G. Baud, S. Salvador, G. Debenest, and J.-F. Thovert. 2015. New granular model medium to investigate smoldering fronts propagation-Experiments. Energy \& Fuels, 29(10), 6780-6792. Copyright 2015 American Chemical Society.]

in mass. These values range from near extinct carbon content to the highest temperature the combustion cell was designed for (Baud et al., 2015). In the other experiments the air flux is varied between $21 \mathrm{~mm} / \mathrm{s}$ and $210 \mathrm{~mm} / \mathrm{s}$ above the bed at $20^{\circ} \mathrm{C}$. One of the points is common. Table 1 summarizes the experimental conditions and main results for the selected experiments. It can be seen that the front temperature varies in a range as large as $709^{\circ} \mathrm{C}$ - which is close to the known extinction temperature of $550^{\circ} \mathrm{C}$ - up to $1465^{\circ} \mathrm{C}$. This last temperature is higher than the maximum cell design value and was unexpected. It counter-intuitively results from the incomplete consumption of oxygen by the front. As the fed air velocity was increased by a factor of 10 , the front velocity increased from $5.2 \mathrm{~mm} / \mathrm{min}$ to $30.4 \mathrm{~mm} / \mathrm{min}$. The ratio of 10 is not retrieved because of the incomplete consumption of oxygen by the front at high air velocity. The experimental velocity of the front is calculated from the time separating the front passage (i.e., maximum temperatures) at successive thermocouples along the cell axis. The stoichiometry of carbon

Table 1. Experimental observations (Exp.) and numerical predictions (Num.).

\begin{tabular}{|c|c|c|c|c|c|c|c|c|c|c|}
\hline \multirow[b]{2}{*}{ Carbon content (\%) } & \multicolumn{6}{|c|}{ Increasing carbon content } & \multicolumn{4}{|c|}{ Increasing Péclet number } \\
\hline & \multicolumn{2}{|c|}{3.6} & \multicolumn{2}{|c|}{3.1} & \multicolumn{2}{|c|}{2.3} & \multicolumn{2}{|c|}{2.3} & \multicolumn{2}{|c|}{2.3} \\
\hline \multirow[t]{2}{*}{ Péclet number } & \multicolumn{2}{|c|}{1.6} & \multicolumn{2}{|c|}{1.6} & \multicolumn{2}{|c|}{1.6} & \multicolumn{2}{|c|}{8} & \multicolumn{2}{|c|}{16} \\
\hline & Exp. & Num. & Exp. & Num. & Exp. & Num. & Exp. & Num. & Exp. & Num. \\
\hline Peak temperature $\left({ }^{\circ} \mathrm{C}\right)$ & 1173 & 1259 & 1066 & 1123 & 709 & 740 & 1056 & 983 & 1465 & 1151 \\
\hline Front velocity $(\mathrm{mm} / \mathrm{min})$ & 5.3 & 4.5 & 5.7 & 4.9 & 5.2 & 5.0 & 17.0 & 17.4 & 31.3 & 33.0 \\
\hline Remaining oxygen (absolute \%vol) & 0.3 & 0 & 0.5 & 0 & 5.5 & 4.3 & 11.4 & 9.3 & 11.3 & 9.7 \\
\hline$f r_{C O}(\% \mathrm{vol})$ & 33.2 & 31.4 & 25.7 & 31.4 & 35.5 & 31.4 & 32.1 & 32.1 & 23.2 & 23.2 \\
\hline Air velocity at $20^{\circ} \mathrm{C}(\mathrm{mm} / \mathrm{s})$ & 21 & 21 & 21 & 21 & 21 & 21 & 105 & 105 & 210 & 210 \\
\hline Consumed carbon (\%) & 100 & 100 & 100 & 100 & 100 & 100 & 100 & 100 & 100 & 100 \\
\hline Front thickness (mm) & 4 & 3 & 4 & 4 & 4 & 6 & 8 & 6 & 10 & 7 \\
\hline
\end{tabular}


consumption by the fed oxygen has been expressed by Kansa et al. (1977), from which the front velocity can be expressed as a function of the experimental parameters (Eq. 2).

$$
v_{f r c}=\frac{v_{g} \rho_{g}}{M_{g}} Y_{O_{2}} f r_{\text {Ooxi }} \frac{M_{C}}{C \rho_{\text {bed }} f r_{\text {Coxi }}\left(1-\frac{f r_{C O}}{2}\right)}
$$

This velocity is called theoretical front velocity in the article, and will be used for stoichiometry checking purposes. It was shown that all of the experiments are in the reaction leading mode, where the chemical front propagates faster than the thermal front. Description of such regimes and others can be found in Aldushin et al. (1980).

It was observed that all of the carbon was oxidized, after the passage of the front, for all of the experiments. It was also observed in Baud et al. (2015) that the temperature at the axis of the combustion cell is significantly higher than close to the walls $(1 \mathrm{~cm}$ away from the walls). This indicates that significant heat losses occur at the cell walls. This will impact discussion on the choice of the model, especially the discussion of $1 \mathrm{D}$ or $2 \mathrm{D}$ approach.

\section{Numerical model}

For the sake of simplicity and to investigate several effects, pore scale modeling was not considered here. Rather, a Darcy scale approach was adopted. As a consequence and as discussed before, it cannot be considered to predict the value of $f r_{C O}$ from the model. Recent studies have not led to this prediction even in Yang and Debenest (2014), where a complete local scale model is used. The proposed approach here is to use the values learned from experiments in the model, under the form of simple functions depending only on the front temperature and on air flux. The carbon combustion reaction is described globally following Eq. (1). We will describe this reaction through an Arrhenius formulation.

The experimental results suggest that important heat losses occur at the cell walls as pointed out before. Therefore, a 2D model and not a simpler 1D model like in Fadaei et al. (2012) was developed. As the insulating layer around the medium is taken into account, the model is indeed expected to bring insights to explain the observed radial temperature gradients and front curving.

The smoldering cell is described in two parts: the reaction medium and the surrounding insulating material. The reacting porous medium is described as a homogeneous domain governed by mass, heat, and momentum conservation laws. The thermal transport equation will be solved simultaneously in the insulating shell. The case was taken as a 2D transient axisymmetrical case. Special care was taken in choosing the boundary conditions, which best described experimental operating conditions (Figure 2).

\section{Heat balance}

According to the experimental conditions, an increase in the flow rate could lead to local nonequilibrium (Debenest et al., 2008). According to Oliveira and Kaviany (2001), combustion in porous media occurs in the large range of time and length scale. As a 


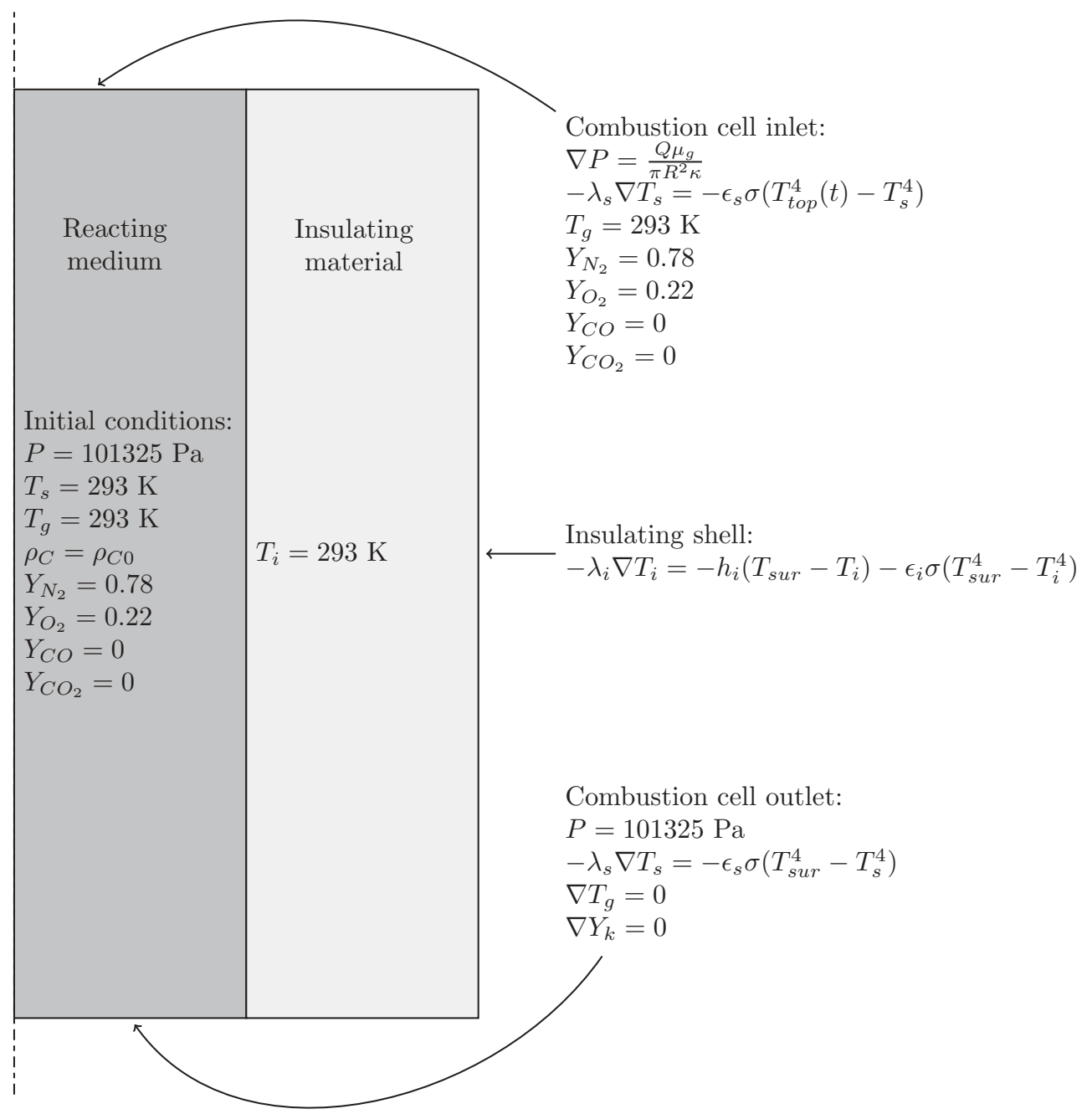

Figure 2. Numerical domain schematic with boundary conditions.

consequence, it usually requires local nonequilibrium formulation. In order to be as general as possible, we develop such an approach. Thus, heat balance is governed by two equations: one for the solid phase (Eq. (3)) and one for the gas phase (Eq. (6)). For the solid:

$$
\frac{\partial(1-\zeta) \rho_{s} c_{p_{s}} T_{s}}{\partial t}=-\nabla \cdot\left(-(1-\zeta) \lambda_{s} \nabla T_{s}\right)+H S\left(T_{g}-T_{s}\right)+\alpha \Pi \omega
$$

where $a$ is the distribution coefficient for heat source. As explained and demonstrated in Michel Quintard (2000), this parameter depends on the ratio $\lambda_{s} / \lambda_{g}$ at the pore scale. Even if the local scale geometry influences this parameter for a high value of this ratio (around 100), most of the heat (i.e., 99\%) is distributed to the solid phase. $\Pi$ is the effective enthalpy depending on the $f r_{C O}$ value. It is calculated as follows:

$$
\Pi=\left(1-f r_{\mathrm{CO}}\right) \Delta \mathrm{h}_{\mathrm{C} \mapsto \mathrm{CO}_{2}}+\mathrm{fr}_{\mathrm{CO}} \Delta \mathrm{h}_{\mathrm{C} \mapsto \mathrm{CO}}
$$

with $\Delta \mathrm{h}_{\mathrm{C} \mapsto \mathrm{CO}_{2}}=32.7910^{6} \mathrm{~J} / \mathrm{kg}, \Delta \mathrm{h}_{\mathrm{C} \mapsto \mathrm{CO}}=9.21010^{6} \mathrm{~J} / \mathrm{kg}$, and $\omega$ is the chemical reaction rate expressed as:

$$
\omega=A e^{\frac{-E a}{R T_{s}}} \rho_{C} Y_{O_{2}}
$$


For the fluid phase:

$$
\frac{\partial \zeta \rho_{g} c_{p_{g}} T_{g}}{\partial t}+\rho_{g} c_{p_{g}} \nabla \cdot\left(\vec{v}_{g} T_{g}\right)=-\nabla \cdot\left(-\zeta \lambda_{\mathrm{g}} \nabla T_{g}\right)-H S\left(T_{g}-T_{s}\right)+(1-\alpha) \Pi \omega
$$

In Eqs.(3) and(6), $\lambda_{s}$ and $\lambda_{\mathrm{g}}$ represent the effective conductivities of the two phases, fluid and solid. Their values depend on the local scale properties of each phase and can be estimated using classical weighted average (Kansa et al., 1977), for instance, or through more complex approaches like upscaling procedures (Quintard et al., 1997). According to Quintard et al. (1997), in nonequilibrium conditions, those properties depend on microstructure, flow, and transfers at the local scale. At low thermal Péclet values, a classical conductive regime is observed with constant value of conductivities. However, increasing the Péclet values, we will observe a dispersive regime. The transition between purely conductive and dispersive regimes depend on the microstructure, but in Quintard et al. (1997), when Péclet remains under 10, the dispersive regime could be ignored.

Thermal Péclet number is a ratio between characterisctic times for conduction and heat convection. It is written as follows:

$$
P e_{t h}=\frac{(\rho C p)_{g}\left\|\vec{v}_{g}\right\| d}{\lambda_{g}}
$$

The thermal Péclet number values range from 2 to 20 for the largest flow rate. However, and according to the results of Quintard et al. (1997), we will not use dispersive models as only one experimental point exceeds $P e_{t h}=10$.

The $f r_{C O}$ parameter was described in the model as follows. The experimental results in Baud et al. (2015) reported in Table 1 showed that changing the carbon content did not impact strongly the value of $f r_{C O}$, and that no clear tendency could be observed. It was decided to keep a constant value of $f r_{C O}$ of $31.4 \%$ vol whatever the carbon content. However, $f r_{C O}$ was observed to vary drastically with air flow variation. The values introduced in the model were $31.4 \% \mathrm{vol}, 32.1 \% \mathrm{vol}$, and $23.2 \% \mathrm{vol}$ for the air velocities of $21 \mathrm{~mm} / \mathrm{s}, 105 \mathrm{~mm} / \mathrm{s}$, and $210 \mathrm{~mm} / \mathrm{s}$, respectively. Thus, $f r_{C O}$ is considered constant throughout the medium and only depends on the flow rate at the inlet.

Several attempts in the literature can be found in order to estimate from the local scale structure, the value of the heat transfer coefficient. For instance, one can find an upscaling study leading to an estimate in idealized media (Quintard et al., 1997). Here, we choose to use classical correlations from the literature (Geb et al., 2012; Eq. (8)).

$$
N u=\frac{4 H \zeta}{S \lambda_{g}}=0.057\left(\frac{4 \rho_{g}|| \vec{v}_{g} \|}{S \mu_{g}}\right)^{0.96} \operatorname{Pr}^{1 / 3}
$$

Considering the porous media to be a bed of monodisperse, geometrical considerations lead to the following expression of the specific surface area:

$$
S=\frac{6(1-\zeta)}{d}
$$

Heat transfer through the insulating shell is described using a classic heat conservation equation: 


$$
\frac{\partial \rho_{i} c_{p_{i}} T_{i}}{\partial t}=-\nabla \cdot\left(-\lambda_{i} \nabla T_{i}\right) \quad \text { in the insulating material }
$$

The coupling between the reacting region and the insulating shell is modeled as a perfect contact. We will assume that the heat is transferred from the solid to the insulating shell. It is described by the following set of equations:

$T_{s}=T_{i} \quad$ on the surface between reacting medium and the insulating material

$-\lambda_{s} \nabla T_{s}=-\lambda_{i} \nabla T_{i}$ on the surface between reacting medium and the insulating material

Finally, the boundary conditions for the insulating material with the ambient conditions are available in Figure 2.

\section{Mass balance in gas phase}

Gas flow through the combustion cell was described using continuity combined with ideal gas assumption and Darcy's law in a similar way to Fadaei et al. (2012) or Lapene et al. (2008).

$$
\frac{\partial \zeta \rho_{g}}{\partial t}+\nabla \cdot\left(\rho_{g} \vec{v}_{g}\right)=\sum_{i, g} \omega_{i, g}
$$

The gas is assumed to behave as an ideal gas, thus its density can be expressed as:

$$
\rho_{g}=\frac{P M_{g}}{\Re T_{g}}
$$

Combining Eqs. (13) and (14), we obtain Eq. (15):

$$
\frac{\partial \frac{\zeta M_{g}}{\Re T_{g}} P}{\partial t}+\nabla \cdot\left(\rho_{g} \vec{v}_{g}\right)=\left(1-f r_{C O}\right) \omega \frac{M_{C O_{2}}-M_{O_{2}}}{M_{C}}+f r_{C O} \omega \frac{M_{C O}-M_{O_{2}}}{2 M_{C}}
$$

In our case, pore Reynolds number varies from 1 to 30 , depending on the flow rate. According to the general Forchheimer equation we have:

$$
\nabla P=\frac{\mu}{\kappa} \vec{v}_{g}+\frac{\rho F}{\mu \sqrt{\kappa}}\left\|\vec{v}_{g}\right\| \vec{v}_{g}
$$

where $F$ is the Forschheimer coefficient accounting for inertial terms at the local scale from drag (Bejan, 1984).

In a recent experimental study (Dukhan et al., 2014), the Forchheimer coefficients were obtained for various media. For spheres packing, with diameter ranging from $1 \mathrm{~mm}$ to $3 \mathrm{~mm}, F$ ranges between $0.43(3 \mathrm{~mm})$ to $0.54(1 \mathrm{~mm})$. Another way is to choose a unique formulation of $\kappa$ depending on the Reynolds number values. According to Chauveteau and Thirriot (1965) and in agreement with the work of Skjetne and Auriault (1999) and Soulaine and Quintard (2014), $\kappa$ in the main flow direction can be correlated, for intermediate Re values, lesser than some hundreds, using:

$$
\kappa^{*}=\frac{\kappa}{1+\gamma \sqrt{R e_{p}}}
$$


According to Soulaine and Quintard (2014), $\gamma$ value is around 0.30 for structured packing and in the case of Dukhan et al. (2014), this varies from 0.11 to 0.14 for, respectively, 1 and $3 \mathrm{~mm}$ spheres packings. It is then possible to use:

$$
\vec{v}_{g}=-\frac{\kappa^{*}}{\mu_{g}} \nabla\left(P-\rho_{g} \vec{g}\right)
$$

Then, combining Eqs. (15) and (18), we obtain Eq. (19):

$$
\frac{\partial \frac{\zeta M_{g}}{\Re T_{g}} P}{\partial t}-\nabla \cdot\left(\rho_{g} \frac{\kappa^{*}}{\zeta \mu_{g}} \nabla\left(P-\rho_{g} \vec{g}\right)\right)=\left(1-f r_{C O}\right) \omega \frac{M_{\mathrm{CO}_{2}}-M_{\mathrm{O}_{2}}}{M_{C}}+f r_{C O} \omega \frac{M_{C O}-M_{O_{2}}}{2 M_{C}}
$$

As densities and viscosities vary in space, we will obtain a nonuniform field of permeability, depending on the flow regime imposed by the mass flux, but also by local thermodynamic conditions.

\section{Mass balance in solid phase}

Solid carbon residue is immobile, and a classical balance equation with reaction is used:

$$
\frac{\partial(1-\zeta) \rho_{C}}{\partial t}=-\omega
$$

At the macro scale, transport of the gaseous species is classically represented by a convection/dispersion equation:

$$
\frac{\partial \zeta \rho_{g} Y_{k}}{\partial t}+\nabla \cdot\left(\rho_{g} \vec{v}_{g} Y_{k}\right)=\nabla \cdot\left(\zeta \rho_{g} \overline{\overline{\mathbf{D}_{\mathbf{k}}^{*}}} \nabla Y_{k}\right)+\omega_{k}
$$

with:

$$
\begin{gathered}
\omega_{\mathrm{O}_{2}}=\left(1-f r_{\mathrm{CO}}\right) \omega \frac{M_{\mathrm{O}_{2}}}{M_{\mathrm{C}}}-f r_{\mathrm{CO}} \omega \frac{M_{\mathrm{O}_{2}}}{2 M_{\mathrm{C}}} \\
\omega_{\mathrm{CO}_{2}}=\left(1-f r_{\mathrm{CO}}\right) \omega \frac{M_{\mathrm{CO}_{2}}}{M_{\mathrm{C}}} \\
\omega_{\mathrm{CO}}=f r_{\mathrm{CO}} \omega \frac{M_{\mathrm{CO}}}{M_{\mathrm{C}}}
\end{gathered}
$$

where $\overline{\overline{\boldsymbol{D}_{\mathbf{k}}^{*}}}$ is a second-order tensor expressed usually as:

$$
\overline{\overline{D_{\mathbf{k}}^{*}}}=\left(\begin{array}{ccc}
D^{T *} & 0 & 0 \\
0 & D^{T *} & 0 \\
0 & 0 & D^{L *}
\end{array}\right)
$$

where $D^{L *}$ is the longitudinal dispersion and $D^{T *}$ the transverse dispersion coefficient. In this study, we will use classical dependence of those coefficients with the flow velocity assuming linear dispersive regime (Quintard et al., 1997). We will ignore extra diagonal terms. These are classically lower than the diagonal terms up to two orders of magnitude (Quintard et al., 1997): 


$$
\begin{aligned}
& D^{L *}=\beta_{L}|| \vec{v}_{g} \|+D^{*} \\
& D^{T *}=\beta_{T}\left\|\vec{v}_{g}\right\|+D^{*}
\end{aligned}
$$

Respectively, $\beta_{L}$ and $\beta_{T}$ are the longitudinal and transverse dipersivities.

$D^{*}$ is the effective diffusion coefficient accounting for the slow down of diffusion due to the microstructure of the porous medium. According to Quintard et al. (1997), in the purely diffusive case, we obtain:

$$
D^{*}=\frac{D}{\tau}
$$

with a tortuosity $\tau$ of 1.14 (Sobieski et al., 2012)

Moreover, when dispersive regimes are linear, we obtain:

$$
D^{k *}=D^{*} I+\left\|\vec{v}_{g}\right\|\left(\beta_{L} \frac{\vec{v}_{k} X \vec{v}_{g}}{\left\|\vec{v}_{g}\right\|^{2}}+\beta_{T} \frac{\vec{v}_{k} X \vec{v}_{g}}{\left\|\vec{v}_{g}\right\|^{2}}\right)
$$

with $\beta_{L}=d$ and $\beta_{T}=d / 10$.

Nitrogen is the diluent specie, so we impose the following constraint:

$$
Y_{\mathrm{N}_{2}}=1-Y_{\mathrm{O}_{2}}-Y_{\mathrm{CO}}-Y_{\mathrm{CO}_{2}}
$$

\section{Physical properties}

Physical properties are available in Tables 2 and 3. Because of the wide range of temperatures that the model has to cover, the evolutions with temperature of several physical properties had to be taken into account (solid and gas thermal conductivities, solid and gas heat capacities, gas diffusivity, and gas viscosity). Correlations coming from the literature or from manufacturer's data were used to describe physical property variations (alumina thermal capacity, Chase, 1998; insulating material-manufacturer's dataThermal Ceramics, 2016; Chen and Churchill, 1963). Radiation inside of the porous bed was taken into account using the Rossland model (Eq. (31); Chen and Churchill, 1963).

Table 2. Reacting medium physical properties.

\begin{tabular}{llcll}
\hline Symbol & \multicolumn{1}{c}{ Name } & Value & Dimension & \multicolumn{1}{c}{ Reference } \\
\hline$\lambda_{\mathrm{Al}_{2} \mathrm{O}_{3}}$ & Alumina thermal conductivity & 0.447 & $\mathrm{~W} / \mathrm{m} / \mathrm{K}$ & Measured \\
$\rho_{s}$ & Sphere density & 1475 & $\mathrm{~kg} / \mathrm{m}^{3}$ & Measured \\
$\zeta$ & Porosity & 0.452 & - & Measured \\
$\kappa$ & Permeability & $2.80910^{-9}$ & $\mathrm{~m}^{2}$ & Estimated with Kozeny Carman law \\
$\tau$ & Tortuosity & 1.14 & - & Sobieski et al. (2012) \\
$S$ & Specific surface area & 1644 & $1 / \mathrm{m}$ & Estimated \\
$d$ & Average sphere diameter & $210^{-3}$ & $\mathrm{~m}$ & Measured \\
$R$ & Reacting medium diameter & $9110^{-3}$ & $\mathrm{~m}$ & Measured \\
$\varepsilon_{s}$ & Emissivity & 0.5 & - & Estimated \\
$T_{\text {sur }}$ & Surrounding temperature & 293 & $\mathrm{~K}$ & Measured \\
\hline
\end{tabular}

Table 3. Insulating material physical properties.

\begin{tabular}{llcll}
\hline Symbol & \multicolumn{1}{c}{ Name } & Value & Dimension & \multicolumn{1}{c}{ Reference } \\
\hline$\rho_{i}$ & Density & 673 & $\mathrm{~kg} / \mathrm{m}^{3}$ & Measured \\
$h_{i}$ & Convective heat transfer coefficient & 10 & $\mathrm{~W} / \mathrm{m}^{2} / \mathrm{K}$ & Estimated as free convection \\
$\varepsilon_{i}$ & Emissivity & 0.1 & - & Estimated \\
\hline
\end{tabular}


The gas phase is a mixture of nitrogen, oxygen, carbon monoxide, and carbon dioxide. As air is used to feed the combustion process, nitrogen content remains high throughout the combustion cell. Thus, nitrogen was taken as the model gas to evaluate gas phase physical properties (thermal capacity, Chase (1998); thermal conductivity, Zimina (1964); dynamic viscosity, Gupta et al. (2003)):

$$
\lambda_{s}=\lambda_{A l_{2} O_{3}}+\frac{16}{3} \zeta d \sigma T_{s}^{3}
$$

\section{Equation system solving and kinetic parameters fitting}

The equation system was solved using implicit sequential algorithms provided by the open source solver Open-FOAM. We use a sequential approach, solving all of the equations step by step. We use an implicit formulation, and we use a second-order numerical scheme. The mesh convergence was achieved using a 60,000-square-cells mesh. The runtime is about $35 \mathrm{~h}$ to produce $2 \mathrm{~h} 30$ of physical time on a single thread. ${ }^{1}$ The kinetic parameters for the carbon oxidation reaction $\mathrm{A}$ and Ea were the only parameters adjusted in the model. Their value was determined to obtain the best fitting between the model predictions and all of the experimental cases considered in the work. To do so, we used three indicators along the cell axis, which were compared to experimental observations: the front temperature, the front velocity, and $\mathrm{O}_{2}$ concentration remaining in the flue gas. To perform this optimization process based on multi-objective analysis, we could use the same approach as in Lapene et al. (2015). However, this requires one to define an objective function and then to determine the best parameters fitted to minimize the errors. This is a dedicated study, and it is not the scope of this article.

Rather, a screen was conducted in order to fit the kinetic parameters for the carbon oxidation reaction $\mathrm{A}$ and $\mathrm{Ea}$. The starting point was the kinetic parameters proposed in Baud et al. (2015): $\mathrm{A}=0.327 \mathrm{1} / \mathrm{s}$ and $\mathrm{Ea}=18,500 \mathrm{~J} / \mathrm{mol}$. Yet, they yielded poor results. It is known from the literature that parameters, even carefully measured, in thermogravimetric experiments may have to be significantly changed in order to yield proper results in bed model (Teixeira et al., 2012). Figure 3 reports the screening results. From this figure, one can see that two main areas emerge: a combustion extinguishment zone (for a given $\mathrm{Ea}$, when $\mathrm{A}$ is too low) and a complete $\mathrm{O}_{2}$ consumption zone (for a given $\mathrm{Ea}$, when $\mathrm{A}$ is too high). The transition zone in between these two zones was investigated to find the best fitting values. In the end, the couple $A=4001 / \mathrm{s}$ and $\mathrm{Ea}$ $=55,500 \mathrm{~J} / \mathrm{mol}$ yielded the best results. Figure 4 shows that with the best fitting parameters a prediction of the three main front characteristics is obtained over the large ranges of experimental parameters. Significant discrepancies can be observed in some cases, but it is judged that they remain acceptable considering the complexity of the smoldering process and the quite simple description adopted in the model. It is stated, at this stage, that the main objective of the work is reached here: it is possible to describe the main characteristics of a smoldering front-including cases where not all of the oxygen is consumed-with a simplified description concerning the chemical

${ }^{1}$ Intel Core i7-4910 MQ Haswell at $2.90 \mathrm{MHz}, 8$ Go DDR3 $1600 \mathrm{MHz}$. 


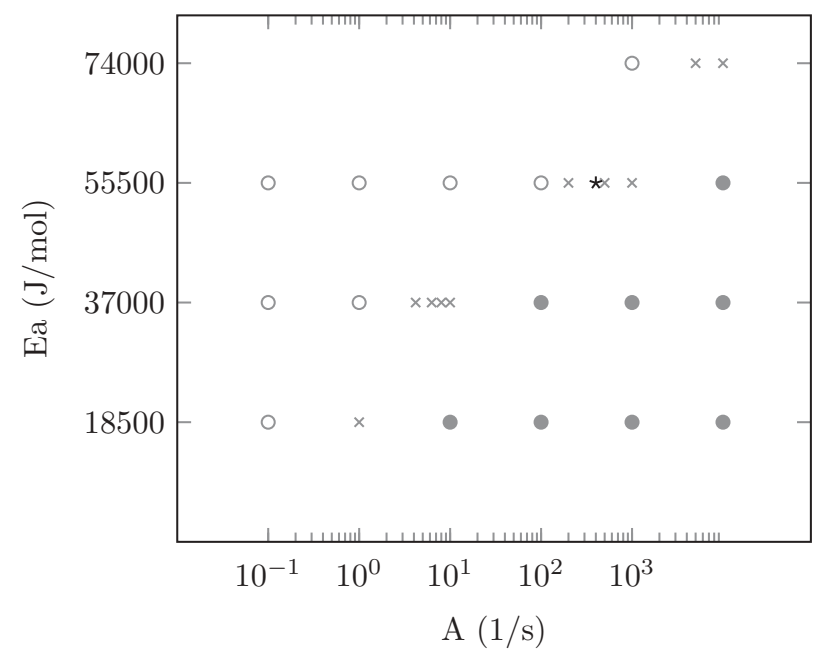

Figure 3. Screening for A and Ea. Open circle: combustion extinction; closed circle: complete oxygen consumption; cross: potential values; star: best fitting values.

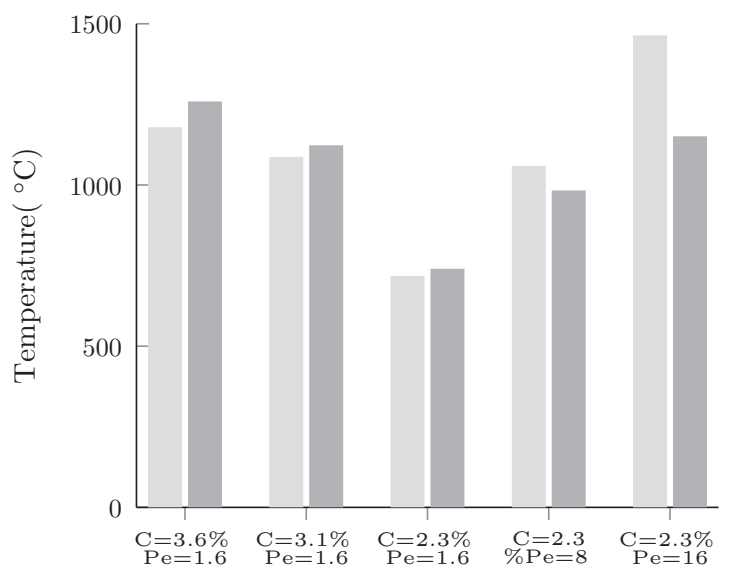

(a) Core temperature

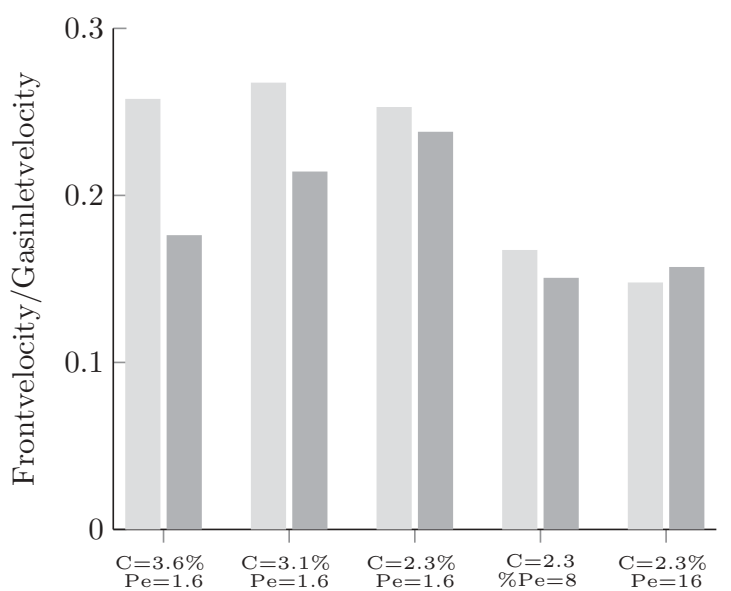

(b) Chemical front velocity

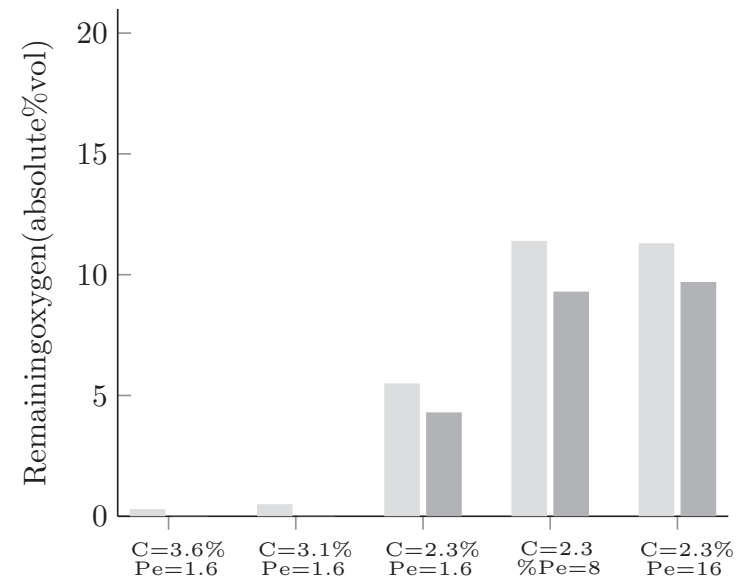

(c) Remaining oxygen after the front

Figure 4. Experimental observation and numerical predictions. Light gray: experimental observations; dark gray: numerical predictions. 
reaction. We remind one here that the $f r_{C O}$ had to be given to the model; this remains the main weak point of the model.

It is interesting here to compare the identified values of $\mathrm{A}$ and $\mathrm{Ea}$ to those determined by Baud et al. (2015) in thermo-gravimetric experiments. These parameters were derived from an isolated particles situation in controlled temperature and oxygen surrounding. The measured activation energy was $18,500 \mathrm{~J} / \mathrm{mol}$, which is approximately three times smaller than the value identified in the model in bed configuration. It is difficult to interpret quantitatively this difference. Nevertheless, it can be concluded that the simple approach consisting of measuring the kinetic parameters on a single particle and injecting them in a bed scale model is not satisfactory. We use a constant activation energy as in Field et al. (1967) who showed that a constant activation energy for carbon oxidation is observed if the temperature does not exceed $1650 \mathrm{~K}$.

In the following section, we will focus our analysis on the coupled phenomena governing the front characteristics and discuss some results by comparison with available experimental data.

\section{Inputs of the model for comprehension of coupled phenomena}

\section{Temperature field}

First, we use a set of conditions in order to establish the ability of our numerical model to capture all the physical phenomena taken into account. We will compare some experimental data to the data of the numerical model:

- the front temperature and width along the axis of the cell at $20 \mathrm{~cm}$ from the inlet;

- radial temperatures, to see if we capture the heat losses;

- temperature signal at the surface of the insulating shell.

Despite the large diameter of the combustion cell used in the experiments, compared to other works in the literature, heat losses at the cell walls have a strong impact. For instance, the computed temperature field after $1 \mathrm{~h}$ is presented in Figures 5 and 6 for the reference case, with $2.30 \% \mathrm{C}$ and $21 \mathrm{~mm} / \mathrm{s}$ air velocity in the reactive bed, and in the insulating shell. The temperature level reaches a maximum on the axis $\left(741 \hat{\mathrm{A}}^{\circ} \mathrm{C}\right)$ then radially decreases to $323 \hat{\mathrm{A}}^{\circ} \mathrm{C}$ at the inner surface of the cell. The transverse profiles exhibit the same information more quantitatively (Figure 6).

Figure 7 reports the temperature history of one thermocouple at the axis of the reacting medium. The experimentally reported history exhibits at first a plateau around $60^{\circ} \mathrm{C}$, which is attributed to water vaporization and condensation (Martins et al., 2010). Then, temperature rises until a peak value of $709^{\circ} \mathrm{C}$ is reached. Afterwards, temperature decreases slowly. The numerical model provides a temperature for both solid and gas phase. These two temperature histories are quite close. It can be explained by the high value of the solid gas convective heat transfer coefficient $(H)$. Yet, gas temperature increases a few moments before solid temperature. This is due to the fact that the gas heats up in contact with the reacting solid, before being pushed forward into the cell. Then, in turn, the gas heats up the solid downstream of the front, which later allows its ignition. This is how the combustion front propagates into the medium. From now on, 


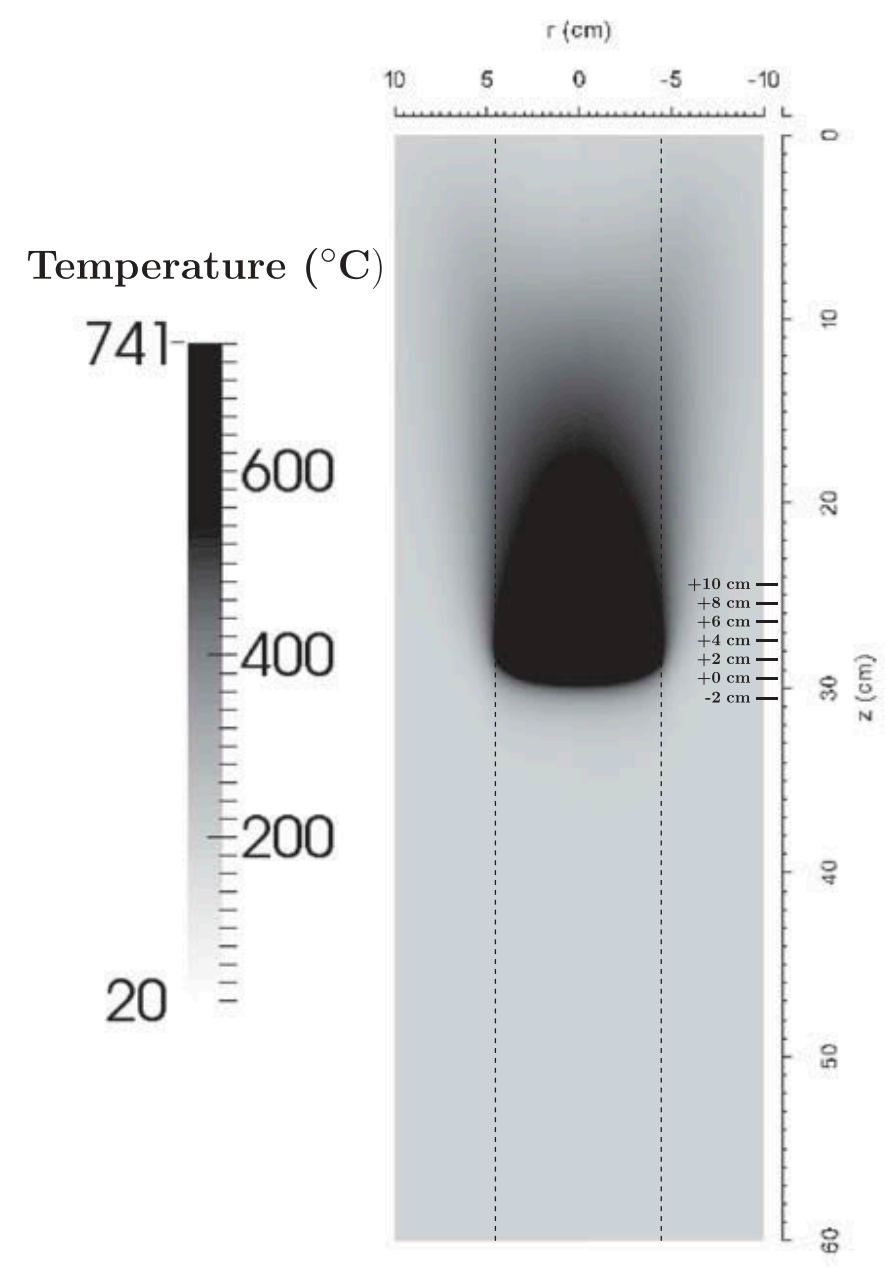

Figure 5. Solid temperature field inside of the combustion cell after $1 \mathrm{~h} . \mathrm{C}=2.3 \%$, $\mathrm{Pe}=1.6$. Locations marked: position relative to the chemical front (as used in Figure 6).

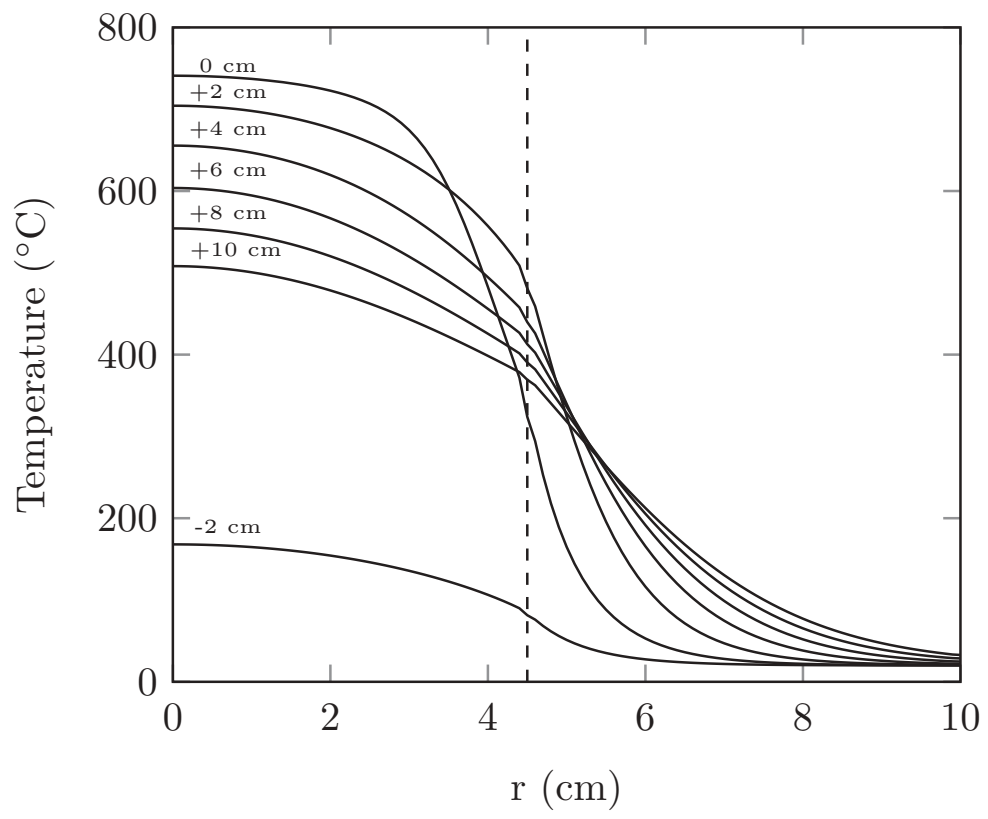

Figure 6. Solid temperature profiles after $1 \mathrm{~h}$ at various locations relative to the front (Figure 5). Front position: $29 \mathrm{~cm} . \mathrm{C}=2.3 \%, \mathrm{Pe}=1.6$. 


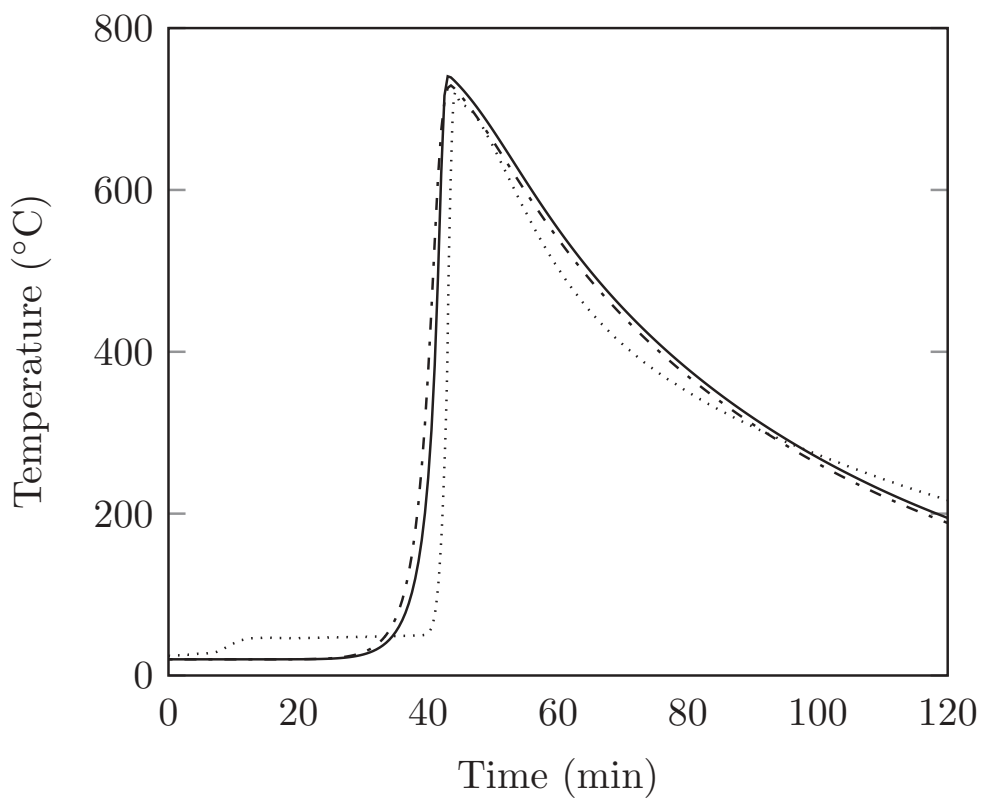

Figure 7. Temperature history on the revolution axis at $19 \mathrm{~cm}$ from the inlet. Continuous line: model solid temperature; dashed line: model gas temperature, model; dotted line: experimental observations. $\mathrm{C}=2.3 \%$, $\mathrm{Pe}=1.6$.

only solid temperature will be considered. Numerically computed temperature history-in which the water vaporization and condensation was not taken into account-shows the same trend as the experimental one. The model predicts a peak temperature of $741^{\circ} \mathrm{C}$, which is very close to the monitored temperature. Agreement between numerical prediction and experimental observations appears then to be very good.

Figure 7 reports the temperature history of one thermocouple at the axis of the reacting medium. The experimentally reported history exhibits at first, a plateau around $60^{\circ} \mathrm{C}$, which is attributed to water vaporization and condensation (Martins et al., 2010). Then, temperature rises until a peak value of $709^{\circ} \mathrm{C}$ is reached. Afterwards, temperature decreases slowly. Numerically computed temperature history-in which the water vaporization and condensation was not taken into account-shows the same trend as the experimental one. The model predicts a peak temperature of $741^{\circ} \mathrm{C}$, which is very close to the monitored temperature. Agreement between numerical prediction and experimental observations appears then to be very good.

In order to check the accuracy of the $2 \mathrm{D}$ model, the experimental history of the thermocouples placed $1 \mathrm{~cm}$ away from the walls inside the reactive medium is reported in Figure 8, together with the model predicted evolution. Experimental observation reports several temperature histories for those thermocouples. Indeed, in the experiments the front can be tilted with respect to the horizontal. Therefore, temperature histories vary according to the angular positions. Once again, a good agreement is obtained. After $40 \mathrm{~min}$, a rapid exponential increase of temperature is observed to reach $650^{\circ} \mathrm{C}$ in several minutes. Then, a slow exponential cooling appears. Values of decay length are given in Baud et al. (2015) depending of the Péclet values. We do not reach the expected level of temperatures with a difference close to $100^{\circ} \mathrm{C}$ for the worst cases. Subsequently, the trends are well captured. Part of the discrepancy can be explained by uncertainties in the insulating heat capacity whose maximum values of the temperature are dependent on. 


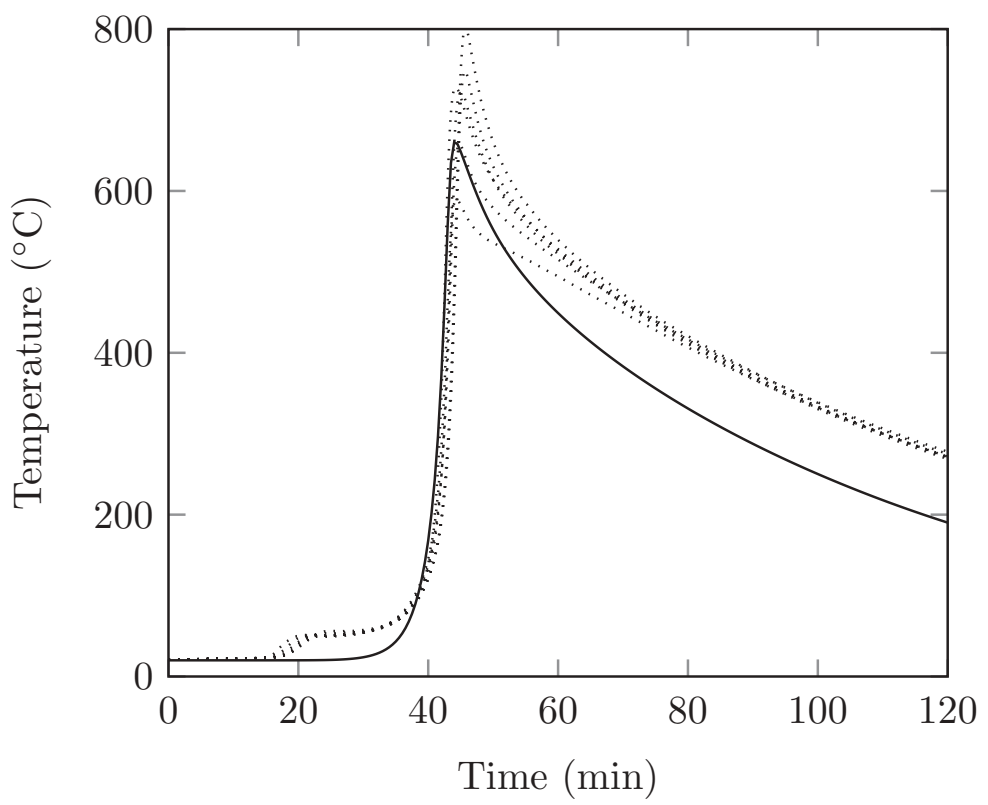

Figure 8. Solid temperature history $1 \mathrm{~cm}$ away from the wall at $19 \mathrm{~cm}$ from the inlet. Continuous line: model; dotted line: experimental observations. $\mathrm{C}=2.3 \%, \mathrm{Pe}=1.6$.

Perfect boundary conditions could also be questionable. We must also keep in mind that $f r_{C O}$ is a constant in our case. A small variation of the value could lead to a large increase in temperature levels, when favoring $\mathrm{CO}_{2}$ formation. This requires the determination of a complex model for $f r_{C O}$, depending on temperature level, for instance. As we focus on determining the principal phenomena involved in the evolution of front shape, we will make the use of this simplified approach.

Capturing the temperature profile of the outer surface of the cell is a token of the quality of the heat loss through the insulating layer modeling. Both experimental observations and numerical predictions are reported in Figure 9. As one can see, the numerical model is able to reproduce the trends of the outer surface temperature history. The predicted outer surface temperature peak is very close to the monitored one: $55^{\circ} \mathrm{C}$ for $60^{\circ} \mathrm{C}$. Thus, we can estimate that our model reproduces fairly well the thermal transport in a complex situation with multi-layered media, heterogeneous in terms of properties.

Based upon this, the model can be used to estimate the amount of energy lost at the walls, compared to the heat released at carbon oxidation. The heat losses at the cell walls were estimated by integrating the heat flux over time, all along the cell. The heat released by carbon combustion can be calculated from the mass of carbon in the cell and the reaction heat calculated from Eq. (4). In the reference case $\mathrm{Pe}=1.6, \mathrm{C}=2.3 \%$; approximately $50 \%$ of the combustion energy is lost through the cell walls. This confirms the necessity of insulating the combustion cell. Even for this quite high diameter cell-as compared to other experimental devices used in the literature-half the energy released is lost and not left in the gas to flow downstream.

As reported in Table 1, the agreement between the model predictions and the experimental observations, in terms of temperature at the center of the cell, is good for all of the cases, except the highest Péclet number. The discrepancy is thought to come from the $f r_{C O}$ values used in the model, which are constant over the medium. $f r_{C O}$ has indeed a strong impact on the heat released by the oxidation reaction and therefore on the temperature. 


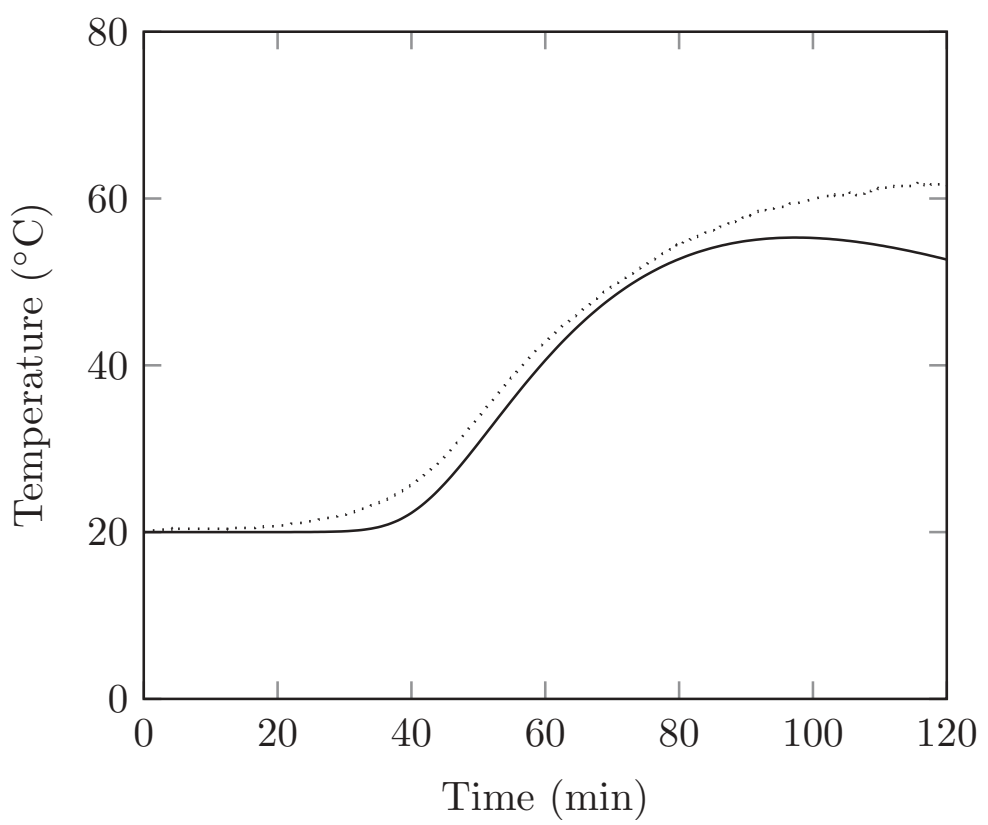

Figure 9. Superimposition of the solid temperature histories on outer surface of the cell at $19 \mathrm{~cm}$ from the inlet. Continuous line: model; dotted line: experimental observations.

Discrepancies for the highest Péclet number case may come also from the fact that thermal dispersive effects were not taken into account. In this particular case, Péclet number value suggested that these effects may play a role on thermal behavior of the medium. As a partial conclusion, our aim was to check if our model was able to capture most of the effects involved in the combustion front propagation. We could assume that our model is really close to the experimental reference and we could now explore making use of it to study the deformation of the front due to heat losses.

\section{Carbon field and front shape}

In order to allow for a general observation of the impact of heat loss on the front shape, a numerical experiment was carried out. Two simulations were run, one with the heat loss enabled and the other with the heat loss disabled. Figure 10 reports the results of this experiment in terms of carbon density field. When heat loss is taken into account, the front shape exhibits a curvature. This curvature is not present when heat loss is missing. From this numerical observation, it can be concluded that heat loss is the source of the front shape curvature.

Using the model, we focus on three configurations to determine the shapes of the smoldering front. Figure 11 reports the modeled shapes of the smoldering front in three extreme configurations. For the reference case (placed at the center) a downward curved front is observed after $10 \mathrm{~cm}$, and is preserved during front propagation, as illustrated at $z=20 \mathrm{~cm}$. The observation is similar with high air flow rate. In the case of high carbon content (left), the front is strongly curved upward; the phenomenon accentuates with the propagation. To support the interpretation of these results, Figure 12 reports the amount of oxygen left in the gas downstream of the front. It can be seen that the situation can shift from total consumption of oxygen to more than half the fed oxygen percolating through 


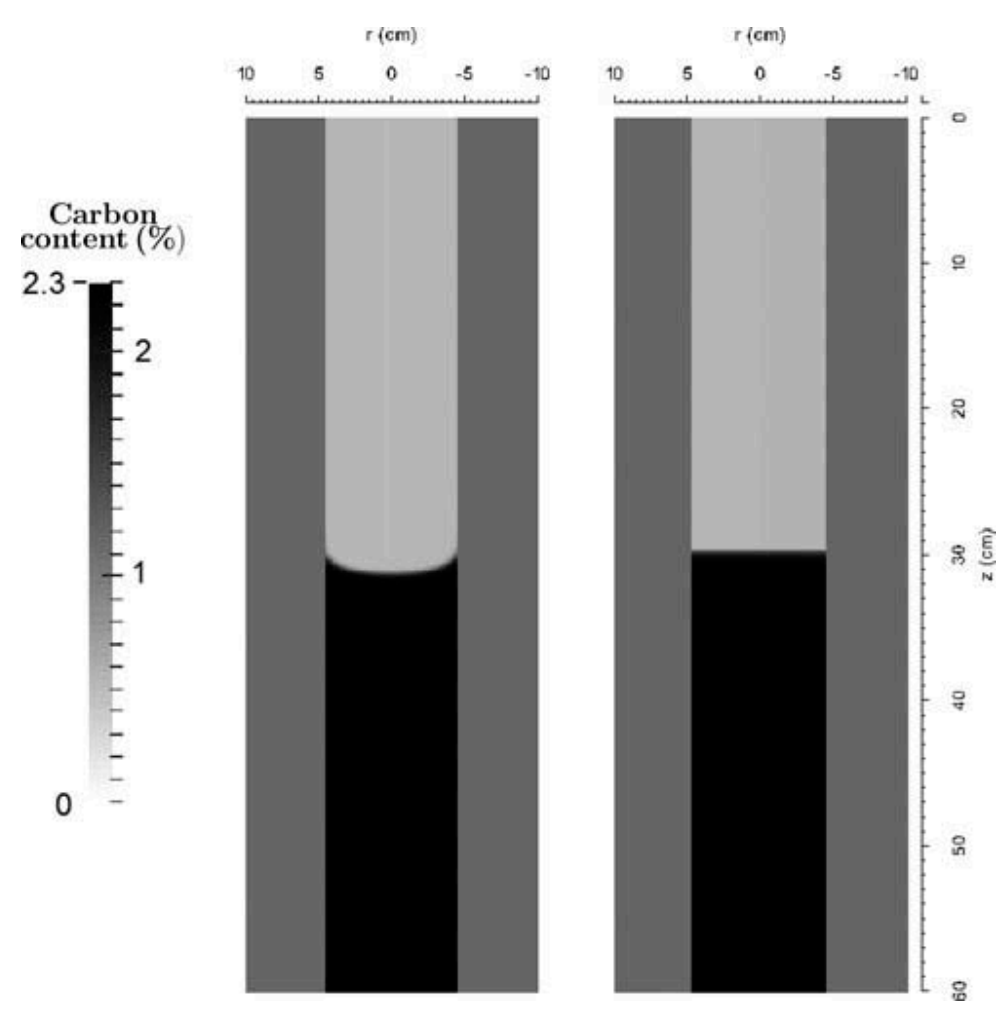

Figure 10. Carbon field inside of the combustion cell when half of the medium has been consumed. On the left: with heat loss. On the right: without the heat loss. Color legend: the darker, the higher.

the front. During the experiments reported by Baud et al. (2015), such curved shapes of the fronts were observed. The curvature was sometimes upward and sometimes downward, even for fixed experimental conditions, such as the reference case. Understanding why a front is not flat is interesting for a man-controlled application because it underlies the front stability question. There are several reasons to explain the front shape change as already discussed in Sennoune et al. (2012). The front velocity is basically controlled by the chemical reaction stoichiometry.

As long as all of the carbon is consumed and all of the fed $\mathrm{O}_{2}$ used, the local front velocity is governed by the local axial oxygen flow rate. The local temperature can impact this flow rate in several ways. If the temperature is lower (as observed closed to the cell walls), the gas density is higher and the front is faster. A low temperature also induces a smaller gas viscosity, favoring high local gas velocity and a faster front propagation.

If not all of the oxygen is consumed at the front, the front will slow down. This is likely to occur if the local temperature is low. If not all of the carbon is oxidized, the front will accelerate.

Sphere packing near the walls is not homogeneous as it is in the bulk of the bed; then permeability is locally increased (White and Tien, 1987). This may lead to an increased gas flow rate and to a local front acceleration.

In the following, it is shown that the developed model can bring valuable understanding of the coupled phenomena governing the front shape evolution.

In the reference case and the high air velocity cases, the front shape is stable. This means that the different phenomena that operate to accelerate and to slow down the front at the walls are balanced. The front shape in the high carbon content experiment is not 


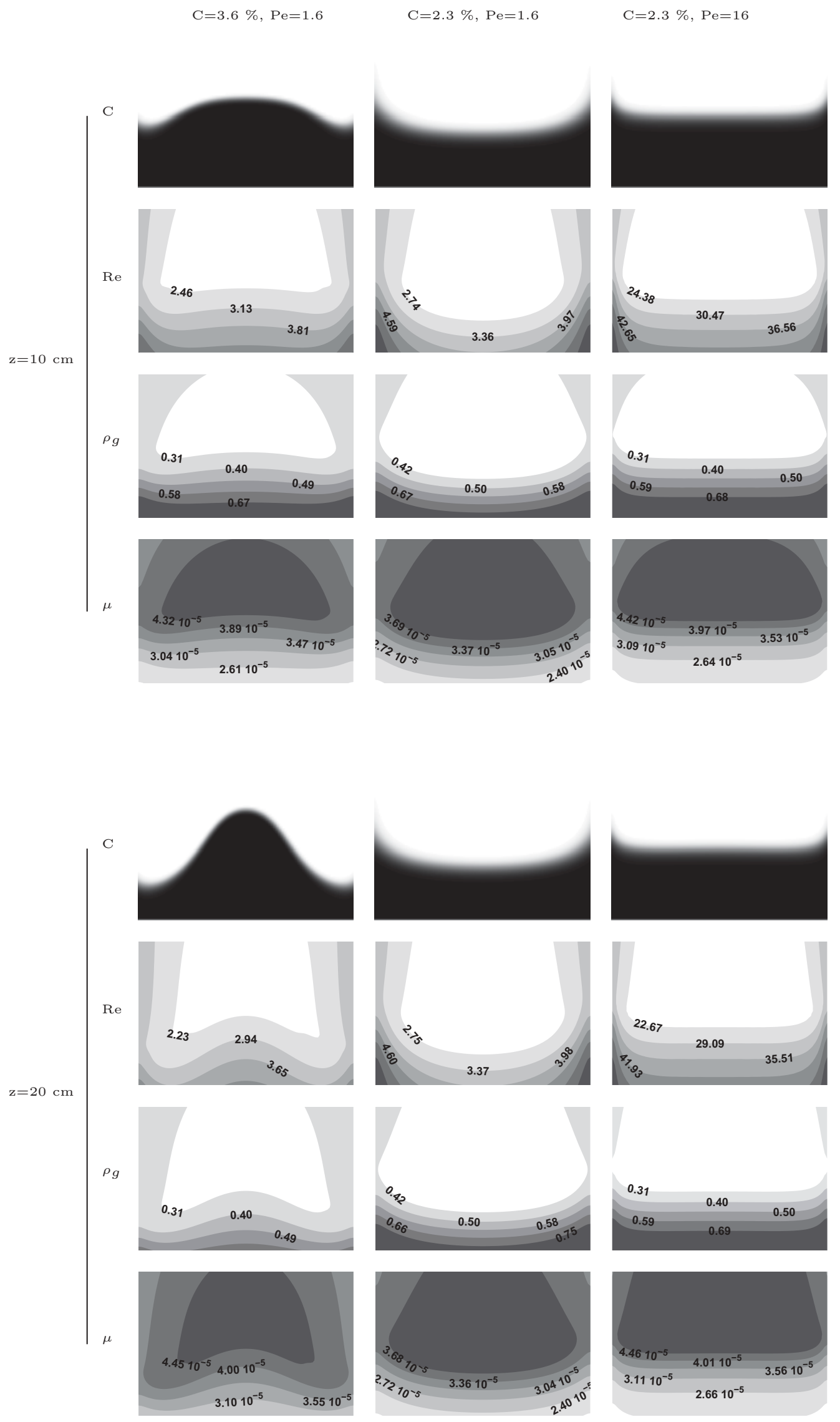

Figure 11. Different fronts shapes, viscosity, density, and Reynolds number maps observed in the reference case (center), with high carbon content (left) and with high gas velocity (right). Color legend: the darker, the higher. 


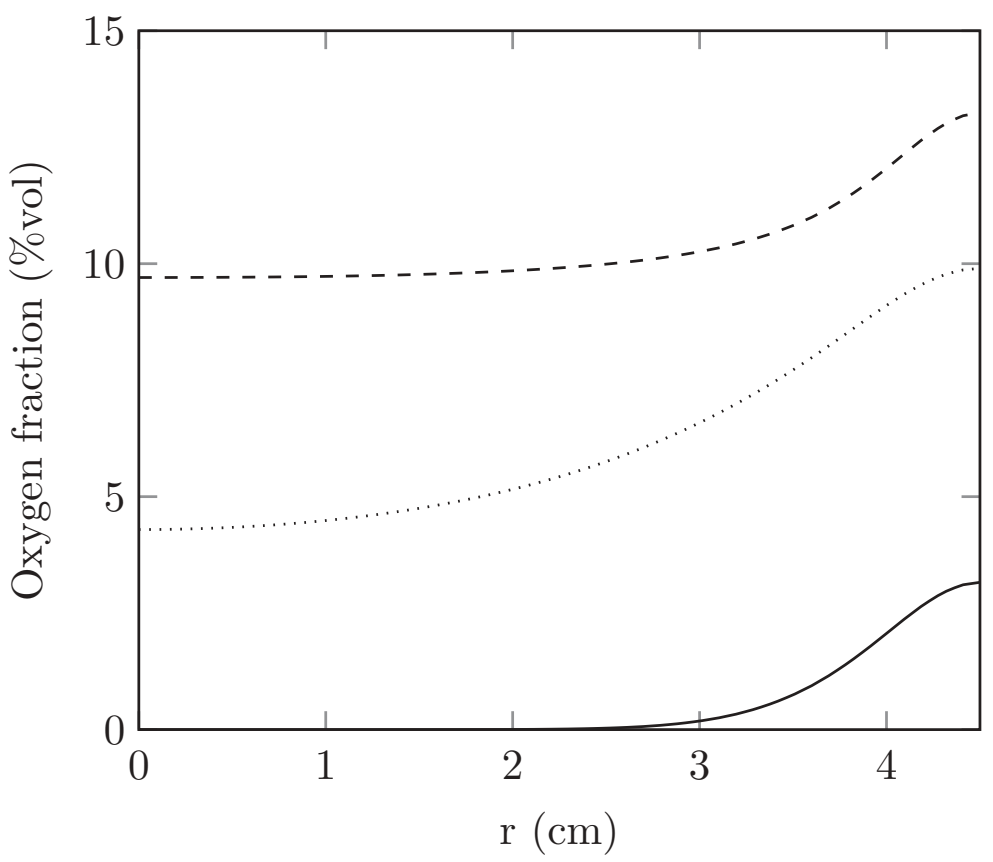

Figure 12. Remaining oxygen downstream of the front. Continuous line: $\mathrm{C}=3.6 \%, \mathrm{Pe}=1.6$; dotted line (reference case): $\mathrm{C}=2.3 \%, \mathrm{Pe}=1.6$; dashed line: $\mathrm{C}=2.3 \%, \mathrm{Pe}=16$.

stable: the front is faster at the walls. The potential phenomenon to slow down the front is the percolation of oxygen at the walls. Indeed, 3.5\% oxygen is predicted by the model at the walls downstream of the front, while no oxygen percolated at the cell axis. This plays a minor role as compared to front accelerating phenomena, i.e., colder temperature of the gases at the walls. It implies that:

- density and oxygen concentrations are higher at the walls;

- the gas viscosity is smaller and the local gas velocity is higher.

The numerical model was used to estimate the contribution of the two phenomena. This remains an indication of the possible effects of both density and viscosity on the front shape. But, in the past, this was mentioned in Fadaei et al. (2012), as well as channeling effects. Even if we exhibit that heat losses are the main phenomenon explaining front curvature, they generate on the fluid properties two important effects:

- higher density at the walls, responsible for three quarters of the front deformation;

- smaller gas viscosity and higher local gas velocity, responsible for one quarter of the deformation.

The proportion of the importance was obtained by inhibiting turn by turn density variation at first, and then viscosity variation.

The sphere arrangement also may explain part of the faster propagation of the front at the walls. Nevertheless, the porosity increase was reported to be in a ratio of about 2 but only in a 1 particle thick zone at the walls (White and Tien, 1987). We believe that this effect was negligible. Hence, it was not implemented in the model. 
Furthermore, the curved shape of the front in high carbon content cases may explain the discrepancies between experimentally reported front velocities at the center of the cell and numerically predicted ones (Table 1). Indeed, the numerical model overpredicts the propagation of the combustion front near the wall for these cases, meaning that oxygen is diverted towards the cell walls. It leads to a lower oxygen flow rate at the center of the cell and, therefore, a lower front velocity at this location. One of the important results here is the determination of this front velocity. Using the signal obtained thanks to thermocouples, combustion front velocity could lead to a bad estimate in the case where the front is curved. We will take, at the axis, the maximum of the recorded temperatures, and then use this as a classic reference for the front location. In this study, we clearly demonstrate that this curvature is important and increases with time depending on several parameters. Determining the real front location is then subject to discussion, but in Table 1 we report not the maximum of the temperatures at the axis but the location of the points, in the longitudinal direction, where $50 \%$ of the carbon is consumed. The stoichiometry of carbon consumption by the fed oxygen has been expressed in Eq. (2) by Sennoune et al. (2012).

It gives the theoretical front velocity as a function of the experimental parameters. According to Baud et al. (2015), these values range from $5(\mathrm{Pe}=1.6), 19 \mathrm{~mm} / \mathrm{min}(\mathrm{Pe}$ $=8)$ to $36.5 \mathrm{~mm} / \mathrm{min}(\mathrm{Pe}=16)$ when carbon content is fixed at $2.3 \%$. The values in Table 1 for the last three cases refer to these points. Then, one could see that our numerical model is close to the observed front temperature but also close to the theoretical ones.

\section{Front thickness}

In order to check the accuracy of our approach, we have one last indicator. This is the front thickness, depending on flow regime (Péclet number) and also on carbon content (values of temperature). It has been investigated in detail by Martins et al. (2010). The front structure was explained and the thickness of the reactive zone reported using gas microsampling.

We quantify this as the distance between the positions where carbon conversion shifts from $10 \%$ to $90 \%$. Table 1 reports the experimentally observed thicknesses in Baud et al. (2015) and the model predicted ones. The present model appears to predict thicknesses comparable to experimental ones, which can vary between 2 and 5 average particle diameters. The model also recovers the increase of the front thickness when air velocity increases. This will be taken here just as a remark, and no particular signification will be attributed to this result. Since the kinetic parameters of the carbon oxidation reaction were fitted, it is not totally surprising that the description of the front thickness has a good order of magnitude. The good description of a very complex pore scale problem by the present Darcy scale model may be accidental to some extent.

\section{Conclusion}

In this study, we develop a fully coupled heat and mass transport model in order to investigate the effects of different phenomena involved when dealing with combustion in porous media. We use a 2D Darcy scale model with a complete description of the whole phenomenology while taking into account heat losses around the reacting medium. We 
use a simplified chemical model based on a single oxidation reaction and a constant value of $f r_{\mathrm{CO}}$. We determine the kinetic parameters by minimizing the error between a set of experiments and the model predictions. The model predictions are satisfying in terms of front temperature, front velocity, and non-consumed oxygen amount over a variety of situations-with different carbon contents and air velocities, including cases in which some oxygen percolates through the front. This clearly demonstrates the ability of this tool to capture the main features of the smoldering process. The remaining discrepancies were mainly attributed to the two weaknesses of the model: a constant $f r_{C O}$ over the domain and a very simplified description of the chemical reaction.

The model was used to bring new understanding of the effect of the heat loss on the front shape. The local cooling at the walls induces a higher gas density, which is the phenomenon controlling the local front shape, with only a minor contribution from the lower gas viscosity. It also enables to quantify the heat loss at the walls that are as high as half of the energy released at carbon oxidation. Accurate description of this loss is necessary to model high temperature smoldering experiments, even in a combustion cell with a diameter as high as $91 \mathrm{~mm}$.

In this work, a very simplified description of the chemical reaction was used, but it required taking the fraction of carbon oxidized into $\mathrm{CO}$ from experiments. In future works, it might be envisioned to prescribe the value of $f r_{C O}$ as a function of local thermodynamic conditions, i.e., gas velocity and temperature level.

\section{Nomenclature}

\section{Latin symbols}

A pre exponential factor(1/s)

$c_{p} \quad$ screen specific heat capacity $(\mathrm{J} / \mathrm{kg} / \mathrm{K})$

C carbon mass fraction in the solid phase

D mass diffusion coefficient $\left(\mathrm{m}^{2} / \mathrm{s}\right)$

D effective mass diffusion coefficient $\left(\mathrm{m}^{2} / \mathrm{s}\right)$

d sphere diameter $(\mathrm{m})$

$\mathrm{Ea}$ activation energy $(\mathrm{J} / \mathrm{mol})$

$\mathrm{fr}_{\mathrm{CO}}$ carbon monoxide fraction

$f r_{C o x i}$ fraction of carbon oxidized by the combustion front

frooxi fraction of oxygen consumed by the combustion front

$\vec{g} \quad$ acceleration due to gravity $\left(\mathrm{m} / \mathrm{s}^{2}\right)$

$H$ solid gas convective heat transfer coefficient $\left(\mathrm{W} / \mathrm{m}^{2} / \mathrm{K}\right)$

$h$ convective heat transfer coefficient $\left(\mathrm{W} / \mathrm{m}^{2} / \mathrm{K}\right)$

$M \quad$ molar mass $(\mathrm{g} / \mathrm{mol})$

$\mathrm{Nu} \quad$ Nusselt number

$P \quad$ pressure $(\mathrm{Pa})$

$P e \quad$ Péclet number

$\mathrm{Pr} \quad$ Prandtl number

Q volumic flow rate $\left(\mathrm{m}^{3} / \mathrm{s}\right)$

$\Re \quad$ ideal gas constant $(\mathrm{J} / \mathrm{mol} / \mathrm{K})$

$R \quad$ reacting medium radius $(\mathrm{m})$ 
Re Reynolds number

$S \quad$ porous medium specific surface area $(1 / \mathrm{m})$

$T$ average macroscale temperature $(\mathrm{K})$

$t$ time (s)

$\vec{v} \quad$ velocity $(\mathrm{m} / \mathrm{s})$

$Y$ mass fraction

\section{Greek symbols}

a distribution coefficient for heat source

$\beta$ dispersiviity $(\mathrm{m})$

$\Delta \mathrm{h}$ latent heat $(\mathrm{J} / \mathrm{kg})$

$\varepsilon \quad$ emissivity

$\omega$ reaction rate $\left(\mathrm{kg} / \mathrm{m}^{3} / \mathrm{s}\right)$

$\lambda$ thermal conductivity $(\mathrm{W} / \mathrm{m} / \mathrm{K})$

$\lambda$ effective thermal conductivity $(\mathrm{W} / \mathrm{m} / \mathrm{K})$

$\kappa \quad$ permeability $\left(\mathrm{m}^{2}\right)$

$\rho$ density $\left(\mathrm{kg} / \mathrm{m}^{3}\right)$

$\sigma \quad$ Stefan-Boltzmann constant $\left(\mathrm{W} / \mathrm{m}^{2} / \mathrm{K}^{4}\right)$

$\Pi$ reaction heat $\left(\mathrm{W} / \mathrm{m}^{3}\right)$

$\mu \quad$ dynamic viscosity (Pa.s)

$\tau$ tortuosity

$\zeta$ porous media porosity

\section{Subscripts}

$\mathrm{Al}_{2} \mathrm{O}_{3}$ alumina

bed bed

frc chemical front

$g \quad$ gas phase

$i \quad$ insulating material

$k$ accounting for the different gaseous species $\left(\mathrm{N}_{2}, \mathrm{O}_{2}, \mathrm{CO}\right.$, and $\left.\mathrm{CO}_{2}\right)$

$L \quad$ longitudinal

$p \quad$ pore

$s \quad$ solid phase

sur surrounding

$T$ transverse

th thermal

top top of the combustion cell

\section{Other symbols}
$\overline{\bar{A}} \quad$ tensors
$\|\vec{a}\| \quad$ vector $\vec{a}$ norm
$\nabla \quad$ nabla operator 


\section{Acknowledgments}

The authors would like to thank Bernard Auduc and Denis Marty for their technical support.

\section{Funding}

The author gratefully acknowlege the French Agence Nationale de la Recherche for financial support of the INSICOMB project ANR-11-BS009-005-01 in which this work was carried on.

\section{ORCID}

Victor Pozzobon (1) http://orcid.org/0000-0003-1530-0834

\section{References}

Akkutlu, I.Y., and Yortsos, Y.C. 2003. The dynamics of in-situ combustion fronts in porous media. Combust. Flame, 134(3), 229-247. DOI: 10.1016/S0010-2180(03)00095-6.

Aldushin, A.P., Seplyarskii, B.S., and Shkadinskii, K.G. 1980. Theory of filtrational combustion. Combust. Explos. Shock Waves, 16(1), 33-40. DOI: 10.1007/BF00756241.

Baud, G., Salvador, S., Debenest, G., and Thovert, J.-F. 2015. New granular model medium to investigate smoldering fronts propagation-Experiments. Energy Fuels, 29(10), 6780-6792. DOI: 10.1021/acs.energyfuels.5b01325.

Bejan, A. 1984. Convective heat transfer. Available at: http://eu.wiley.com/WileyCDA/WileyTitle/ 495 productCd-047157709X.html.

Chase, M.W. 1998. NIST-JANAF Thermochemical Tables, 4th ed., American Chemical Society, American Institute of Physics for the National Bureau of Standards, Washington, D.C.

Chauveteau, G., and C. Thirriot, C. 1965. Sur les Pertes de Charge en Écoulement Laminaire Dans Quelques Géométries Simple et Dans le Milieu Poreux, Trieste Edition, Trieste, Italy.

Chen, J.C., and Churchill, S.W. 1963. Radiant heat transfer in packed beds. AIChE J., 9(1), 35-41. DOI: 10.1002/aic.690090108.

Debenest, G., Mourzenko, V.V., and Thovert, J.F. 2005. Smouldering in fixed beds of oil shale grains: Governing parameters and global regimes. Combust. Theor. Model., 9(2), 301-321. DOI: $10.1080 / 13647830500098365$.

Debenest, G., Mourzenko, V.V., and Thovert, J.-F. 2008. Three-dimensional microscale numerical simulation of smoldering process. Combust. Sci. Technol., 180(12), 2170-2185. DOI: 10.1080/ 00102200802414956.

Dukhan, N., Bağcl, Ö., and Özdemir, M. 2014. Experimental flow in various porous media and reconciliation of Forchheimer and Ergun relations. Exp. Therm. Fluid Sci., 57, 425-433. DOI: 10.1016/j.expthermflusci.2014.06.011.

Elayeb, M. 2008. Modélisation à l'échelle microscopique de transports avec réaction en milieu poreux: Combustion en lit fixe. PhD thesis, Université de Poitiers, Poitiers Cedex, France.

Fadaei, H., Sennoune, M., Salvador, S., Lapene, A., and Debenest, G. 2012. Modelling of nonconsolidated oil shale semi-coke forward combustion: Influence of carbon and calcium carbonate contents. Fuel, 95(1), 197-205. DOI: 10.1016/j.fuel.2011.11.066.

Field, M., Gill, D., Morgan, B., and Hawksley, P. 1967. Combustion of Pulverized Fuel, British Coam Utilization Research Association, Chelthenham, Gloucestershire, UK, pp. 155-173.

Geb, D., Zhou, F., and Catton, I. 2012. Internal heat transfer coefficient determination in a packed bed from the transient response due to solid phase induction heating. J. Heat Transfer, 134(4), 042604-042604. DOI: 10.1115/1.4005098.

Gupta, M., Yang, J., and Roy, C. 2003. Specific heat and thermal conductivity of softwood bark and softwood char particles. Fuel, 82(8), 919-927. DOI: 10.1016/S0016-2361(02)00398-8. 
Hasan, T., Gerhard, J.I., Hadden, R., and Rein, G. 2015. Self-sustaining smouldering combustion of coal tar for the remediation of contaminated sand: Two-dimensional experiments and computational simulations. Fuel, 150, 288-297. DOI: 10.1016/j.fuel.2015.02.014.

Kansa, E., Perlee, H., and Chaiken, R. 1977. Mathematical-model of wood pyrolysis including internal forced convection. Combust. Flame, 29(3), 311-324. DOI: 10.1016/0010-2180(77) 90121-3.

Lapene, A., Debenest, G., Quintard, M., Castanier, L.M., Gerritsen, M.G., and Kovscek, A.R. 2015. Kinetics oxidation of heavy oil. 2. Application of genetic algorithm for evaluation of kinetic parameters. Energy Fuels, 29(2), 1119-1129. DOI: 10.1021/ef501392k.

Lapene, A., Debenest, G., Quintard, M., Martins, M., and Salvador, S. 2008. Numerical simulation of combustion in reactive porous media. IRECHE, 12, 803-813.

Maerefat, M., El-Hossaini, M.K., and Mazaheri, K. 2011. Numerical modeling of two-dimensional cylindrical porous radiant burners with sidewall heat losses. J. Porous Media, 14(4), 317-327.

Mailybaev, A.A., Bruining, J., and Marchesin, D. 2011. Analysis of in situ combustion of oil with pyrolysis and vaporization. Combust. Flame, 158(6), 1097-1108. DOI: 10.1016/j. combustflame.2010.10.025.

Martins, M.F., Salvador, S., Thovert, J.-F., and Debenest, G. 2010. Co-current combustion of oil shale-Part 2: Structure of the combustion front. Fuel, 89(1), 133-143. DOI: 10.1016/j.fuel. 2009.06.040.

Michel Quintard, B.L. 2000. Effect of homogeneous and heterogeneous source terms on the macroscopic description of heat transfer in porous media. In Symposium on Energy Engineering in the 21st Century, Vol. 2, Begell House, New York, pp. 482-489.

Oliveira, A.A.M., and Kaviany, M. 2001. Nonequilibrium in the transport of heat and reactants in combustion in porous media. Prog. Energy Combust. Sci., 27(5), 523-545. DOI: 10.1016/S03601285(00)00030-7.

Page, S.E., Siegert, F., Rieley, J.O., Boehm, H.-D.V., Jaya, A., and Limin, S. 2002. The amount of carbon released from peat and forest fires in Indonesia during 1997. Nature, 420(6911), 61-65. DOI: $10.1038 /$ nature01131.

Pironi, P., Switzer, C., Rein, G., Fuentes, A., Gerhard, J.I., and Torero, J.L. 2009. Small-scale forward smouldering experiments for remediation of coal tar in inert media. Proc. Combust. Inst., 32(2), 1957-1964. DOI: 10.1016/j.proci.2008.06.184.

Quintard, M., Kaviany, M., and Whitaker, S. 1997. Two-medium treatment of heat transfer in porous media: Numerical results for effective properties. Adv. Water Resour., 20(2-3), 77-94. DOI: 10.1016/S0309-1708(96)00024-3.

Rein, G., Cleaver, N., Ashton, C., Pironi, P., and Torero, J.L. 2008. The severity of smouldering peat fires and damage to the forest soil. CATENA, 74(3), 304-309. DOI: 10.1016/j.catena.2008.05.008.

Schult, D., Matkowsky, B., Volpert, V., and Fernandezpello, A. 1995. Propagation and extinction of forced opposed flow smolder waves. Combust. Flame, 101(4), 471-490. DOI: 10.1016/ 0010-2180 (94)00239-O.

Schult, D.A., Bayliss, A., and Matkowsky, B.J. 1998. Traveling waves in natural counterflow filtration combustion and their stability. SIAM J. Appl. Math., 58(3), 806-852.

Sennoune, M., Salvador, S., and Debenest, G. 2011. Impact of a $\mathrm{CO}_{2}$-enriched gas on the decarbonation of $\mathrm{CaCO}_{3}$ and the oxidation of carbon in the smoldering process of oil shale semicoke. Energy Fuels, 26(1), 391-399.

Sennoune, M., Salvador, S., and Debenest, G. 2012. Impact of a $\mathrm{CO}_{2}$-enriched gas on the decarbonation of $\mathrm{CaCO}_{3}$ and the oxidation of carbon in the smoldering process of oil shale semicoke. Energy Fuels, 26(1), 391-399. DOI: 10.1021/ef201304n.

Skjetne, E., and Auriault, J.-L. 1999. High-velocity laminar and turbulent flow in porous media. Transp. Porous Media, 36(2), 131-147. DOI: 10.1023/A:1006582211517.

Sobieski, W., Zhang, Q., and Liu, C. 2012. Predicting tortuosity for airflow through porous beds consisting of randomly packed spherical particles. Transp. Porous Media, 93(3), 431-451. DOI: 10.1007/s11242-012-9961-8. 
Soulaine, C., and Quintard, M. 2014. On the use of a Darcy-Forchheimer like model for a macroscale description of turbulence in porous media and its application to structured packings. Int. J. Heat Mass Transfer, 74, 88-100. DOI: 10.1016/j.ijheatmasstransfer.2014.02.069.

Teixeira, G., Salvador, S., and Van de Steene, L. 2012. Gazéification de charbon de granules de bois: Comportement thermochimique et mécanique d'un lit fixe continu. PhD thesis. INP Toulouse, Toulouse.

Thermal Ceramics. 2016. Organic RCF Vacuum Formed Products. Available at: http://www.mor ganthermalceramics.com/sites/ default/files/datasheets/mgam_5-14-700_kaowoolbands.pdf.

Vantelon, J.-P., Lodeho, B., Pignoux, S., Ellzey, J.L., and Torero, J.L. 2005. Experimental observations on the thermal degradation of a porous bed of tires. Proc. Combust. Inst., 30(2), 2239-2246. DOI: $10.1016 /$ j.proci.2004.08.109.

White, S.M., and Tien, P.C.L. 1987. Analysis of flow channeling near the wall in packed beds. Wärme-Stoffübertragung, 21(5), 291-296. DOI: 10.1007/BF01009290.

Yang, C., and Debenest, G. 2014. Numerical simulations for smoldering in a horizontal channel: Comparisons between variable density-based formulation and incompressible one. Combust. Sci. Technol., 186(12), 1954-1974. DOI: 10.1080/00102202.2014.930028.

Yang, C., Thovert, J.-F., and Debenest, G. 2015. Upscaling of mass and thermal transports in porous media with heterogeneous combustion reactions. Int. J. Heat Mass Transfer, 84, 862-875. DOI: 10.1016/j.ijheatmasstransfer.2015.01.043.

Zajdlik, R., Jelemensky, L., Remiarova, B., and Markos, J. 2001. Experimental and modelling investigations of single coal particle combustion. Chem. Eng. Sci., 56(4), 1355-1361. DOI: 10.1016/S0009-2509(00)00358-4.

Zimina, N. 1964. Thermal conductivity of nitrogen at high temperatures. Teplofiz. Vys. Temp., 2, 869-878. 